\title{
Relationship Between IPSS (International Prostatic Symptomatic Score) and Quality of Life in Patients with LUTS (Lower Urinary Tract Symptoms)
}

\author{
Irfansyah $^{1}$, Didit Pramudhito ${ }^{1 *}$ \\ ${ }^{1}$ Department of Surgery, Faculty of Medicine, Universitas Sriwijaya \\ *Corresponding Author Email: diditdhito@gmail.com
}

\begin{abstract}
Introduction. Lower urinary tract symptoms (LUTS) is the most common problem in men with age and can reduce quality of life due to various complaints on micturition.

Method. This study was a cross sectional study conducted in May-July 2018 at the Urology Outpatient Clinic, Dr. Mohammad Hoesin Hospital Palembang and 36 samples were obtained. The technique of data collection was done by filling out the questionnaire. Analysis of data in the form of descriptive for general characteristics and correlation analysis used is the Spearman Rank test correlation.
\end{abstract}

Results: The most prevalence of benign prostate hyperplasia (BPH) occurred in the age group 7180 years as many as 12 patients $(33.3 \%)$. BPH patients who came with the most LUTS experienced severe degrees of International Prostatic Symptomatic Score (IPSS) (24 patients, 66.7\%). There were 16 patients (44.4\%) felt their quality of life was very poor. Spearman Rank correlation test showed no significant relationship between IPSS with the quality of life of patients with BPH with $\operatorname{LUTS}(\mathrm{p}>0.05, \mathrm{r}=0.073)$ 


\section{SSS SRIWIJAYAJOURNABOPSURGERY}

Conclusion. There was no significant relationship between IPSS with the quality of life of BPH patients with LUTS.

Keywords. lower urinary tract symptoms, benign prostate hyperplasia, international prostatic symptomatic score

\section{Introduction}

Benign prostatic hyperplasia (BPH) is the main disease that most often occurs in men with age. ${ }^{1} \mathrm{BPH}$ is a non-malignant enlargement of the prostate gland (stromal hyperplasia and glandular epithelium) that occurs in the periurethra prostate transition zone surrounding the urethra. ${ }^{2}$ Clinically, BPH can cause lower urinary tract symptoms (LUTS) symptoms which consist of irritative and obstructive symptoms. In general, the symptoms that are often seen are nocturia and weak urinary stream and sensation of urination that is unsatisfied. Prolonged obstruction can result in acute urinary retention, recurrent urinary tract infections, hematuria, bladder stones, and renal insufficiency. ${ }^{2,3}$

At the age of 50 years, found $50 \%$ of men suffer from BPH and $90 \%$ obtained at the age of 80 years, and the highest incidence occurred in the age range 70-79 years. ${ }^{1,2}$ Population data in Canada shows an increase in outpatient patient visits BPH of 50\% between 2000-2004.4 In the UK, out of 1500 men aged 50 years or older, $41 \%$ obtained LUTS symptoms. ${ }^{4,5}$ According to the Korea National Statistical Office, the proportion of Koreans with BPH aged 65 years or more was $5.9 \%$ in 1995 and $7.2 \%$ in 2001 and is predicted to increase by $14.4 \%$ in $2019 .{ }^{6-9}$ The exact number of BPH events in Indonesia has never been investigated, but as an illustration of hospital prevalence in Cipto Mangunkusumo Hospital (RSCM) from 1994-2013 there were 3,804 cases with an average age of patients aged 66.61 years. In economic terms, BPH was estimated to have incurred significant health costs. In the United Kingdom, around $£ 62-£ 91$ million is spent each year on BPH, and in the United States it is estimated that costs incurred exceed US \$ 4 billion annually.6.7 In Japan, medical management related to BPH disease costs 80 million yen. ${ }^{8}$ 


\section{STS SRIWIJAYA JOURNAB OFEURGERY}

BPH occurs in the transitional zone where epithelial and stromal cells attach. The growth of these cells is influenced by sex hormones and cytokine responses. ${ }^{10}$ In the prostate, testosterone is converted to Dihydrotestosterone (DHT), androgens are the main mediators of prostate hyperplasia. The role of DHT becomes clear when BPH sufferers are treated with orchidectomy and 5-alpha-reductase inhibitors (inhibiting the conversion of testosterone to DHT) showing a decrease in BPH symptoms. The role of DHT can be seen in men with BPH where DHT levels are found to be higher than those with normal prostate size. ${ }^{11}$ Androgen levels in plasma decrease with age, more data are needed to prove why BPH occurs when men get more get older. Estrogen plays an important role in $\mathrm{BPH}$, it enters stromal cells through the mechanism of estrogen receptors. The ratio of estrogen to androgens increases with age, this explains why BPH occurs in old age. ${ }^{12}$

Cytokines play a role in prostate enlargement by stimulating the inflammatory response and epithelial growth factor. When the prostate enlarges due to hyperplasia, the urethra is compressed which ultimately causes urinary retention. Patients experience bladder hyperactivity, inflammation, and distension due to bladder smooth muscle cells enlarging in response to prostate obstruction. This causes oxidative stress and the formation of free radicals, alfa-adrenergic nerve bladder changes, resulting in symptoms of storage. When bladder smooth muscle cells can no longer adapt, smooth muscle contractions become worse and voiding symptoms dominate.

Several symptom scoring systems have been developed to assess the severity of symptoms. ${ }^{13}$ This scoring system is not a tool for diagnosing BPH, but is an objectively valid tool for assessing patient symptoms, determining the therapeutic choice of patients with LUTS-BPH and monitoring the effects of intervention in treatment procedures. The most widely used scoring system is the International Prostatic Symptom Score (IPSS), developed by the American Urological Association (AUA) and adopted by the World Health Organization (WHO). ${ }^{14}$ IPSS provides an assessment of seven characteristics of BPH symptoms. Total scores indicate the severity of the disease (1-7 mild, 8-19 moderate, 20-35 severe). ${ }^{15}$

$\mathrm{BPH}$ risk factors in general are old age, functioning testes, metabolic syndrome, family history of BPH, obesity, history of diabetes, and black race. ${ }^{10,16}$ Patient's diet, smoking and exercise can influence the development of BPH. ${ }^{10,17,18}$ Patients who consume a high fiber diet have a lower 


\section{STS SRIWIJAYAJOURNAB OFEURGERY}

risk of symptoms of BPH compared to those who do not, although fruit consumption does not show a significant relationship to the severity of BPH. High-meat diets have a significant relationship to the severity of BPH. Studies also show that alcohol consumption can increase the risk of $\mathrm{BPH}{ }^{10}$

LUTS such as urinary hesitancy, intermittent, weak urine emission, nocturia, increasing frequency, urgency, and sensation of emptying of urine that are not lampias. These symptoms significantly influence the quality of life (QoL) of BPH sufferers. Although BPH is not a lifethreatening disease, it affects QoL in various ways. These QoL disorders include mainly nocturia, disorders due to urine frequency, psychological disorders due to urgency, uncomfortable sex life, and fear due to prostate tumors. ${ }^{20}$

Not all men feel disturbed by LUTS, and finally they do not seek medical treatment. In some cases, this symptom can be accepted as a natural occurrence with aging and learning to live it. ${ }^{21}$ According to Nugroho (2002), the delay in early detection is influenced by patients' perceptions of complaints that are felt and often ignored, so that the situation can affect quality sufferers' lives. ${ }^{21,22}$ According to Christie $S$ et al (2014) there is a significant correlation between IPSS and QoL. ${ }^{21}$ Similar to the study conducted by CS Agrawal et al (2008) which says there is a strong relationship between IPSS and Qol scores. ${ }^{23}$ But in the study they were not shown other confounding variables such as prostate size, education, and occupation which could provide different perceptions of IPSS and Qol disturbance. In a study in the United States, 29\% of BPH patients did not go to the doctor because they did not understand the symptoms experienced was

prostate enlargement. ${ }^{20}$ The work showed an association with Qol scores. Qol is decreased in patients who are still actively working compared to those who have retired.20 Research in Nepal shows no relationship between prostate volume and Qol. ${ }^{23}$

\section{Methods}

This study was a correlation test study using a cross-sectional design to determine the correlation between IPSS scores with quality of life. The study subjects (36 people) were all BPH sufferers who came with LUTS complaints at the outpatient clinic of urology, dr Moh Husein 


\section{SSS SRIWIJAYAJOURNABOPSURGERY}

general hospital Palembang, who met the inclusion and exclusion criteria. Inclusion criteria were patients with a diagnosis of BPH who came with LUTS complaints, BPH patients aged between 45-80 years, patients willing to follow the study and sign informed consent. Exclusion criteria were $\mathrm{BPH}$ patients who present with urinary retention and urethral catheters.

LUTS assessment using IPSS, is one of the prostate symptom scoring systems developed by the American Urological Association (AUA) and has been approved by WHO in the form of a questionnaire containing seven indices of LUTS symptoms, the results are categorized as mild if the score is $0-7$, moderate if the score is $8-19$, weight if the score is 20-35. Quality of life assessment uses the quality of life score, the results are categorized as very happy, happy, generally satisfied, mixed between satisfied and dissatisfied, generally not satisfied, not happy and very bad.

Univariate analysis was carried out aimed at describing each of the variables studied in the form of a frequency distribution table. Bivariate analysis is a statistical method to find out the relationship between independent variables and dependent variables. Data obtained from the results of the study will be analyzed by Spearman rank correlation test, this test is used to measure the level or close relationship between the two variables on an ordinal scale. Multivariate analysis was carried out to see which independent variable was the closest to the dependent variable following on from the bivariate analysis. The statistical test used is multiple linear regression.

\section{Results}

BPH sufferers who came with LUTS complaints had the most severe IPSS score (20-35) of 24 people (66.7\%) and the rest were moderate IPSS scores (8-19) of 12 people (33.3\%). Based on the quality of life score (QoL) which shows that 8 patients $(22.2 \%)$ felt their quality of life was generally not satisfied, followed by 12 patients (33.3\%) who felt their quality of life was not happy, then 16 patients $(44.4 \%)$ who feel terrible about their quality of life. In this study, there were no BPH sufferers with LUTS complaints who felt that their quality of life was very happy, happy, generally satisfied or mixed between satisfied and dissatisfied. 


\section{SSS SRIWIJAYA JOURNAB OFEURGERY}

Table 1. IPSS Characteristics and Quality of Life

\begin{tabular}{|c|c|c|}
\hline QoL Score & Number of Patient & Percentage \\
\hline Very happy (0) & 0 & 0 \\
\hline Happy (1) & 0 & 0 \\
\hline Generally satisfied (2) & 0 & 0 \\
\hline Mixed of satisfied and unsatisfied (3) & 0 & $22.2 \%$ \\
\hline Generally unsatisfied (4) & 8 & $33.3 \%$ \\
\hline Bad (5) & 12 & $44.4 \%$ \\
\hline Very bad (6) & 16 & Percentage \\
\hline IPSS & Frequency & 0 \\
\hline Moderate 8-19 & 0 & $33.3 \%$ \\
\hline Severe 20-35 & 12 & $66.7 \%$ \\
\hline
\end{tabular}

Table 2. Corelation between IPSS and Quality of Life

\begin{tabular}{|l|l|l|}
\hline Correlation between & $\mathrm{p}^{*}$ & $\mathrm{r}$ \\
\cline { 1 - 2 } IPSS & 0.674 & 0.073 \\
\cline { 1 - 2 } Quality of Life & & \\
\hline
\end{tabular}

* Spearman's rho correlation, significant if $\mathrm{p}<0.05$. $€$ Correlation strength: very weak $(\mathrm{r}<0.20)$, weak (r: $0.20-0.39)$, moderate (r: $0.40-0.59)$, strong (r: $0.60-0.79)$, very strong $(r \geq 0.80)$

Table 2 presents data about the relationship between IPSS scores and quality of life. There is no significant relationship between IPSS scores with quality of life.

\section{Discussion}

The distribution of patients based on quality of life scores showed that 16 patients $(44.4 \%)$ felt very bad about their quality of life, followed by 12 patients $(33.3 \%)$ who felt quality of life 
was not happy. Different results were obtained from research conducted by Christie S Mandang et al (2014) that most 10 patients (27\%) were unhappy with their quality of life. ${ }^{21}$

Spearman correlation test was performed between age and prostate volume, a significant correlation was obtained ( $\mathrm{p}<0.05$ ) with a correlation value of 0.707 , which means there was a significant relationship between age and prostate volume. This is different from the results obtained by CS Agrawal (2008) where there was no significant relationship between age and prostate volume $(\mathrm{p}=0.656$ and $\mathrm{r}=0.045) .^{23}$

A correlation test was also performed between prostate volume and IPSS score, and we did not get a significant relationship between the two $(\mathrm{p}=0.614$ and $\mathrm{r}=-0.087)$. This is similar to research conducted by CS Agrawal (2008), that there is no relationship between prostate volume and IPSS $(\mathrm{p}=0.57$ and $\mathrm{r}=0.191) .{ }^{23}$

IPSS and quality of life scores are used to determine the basis of BPH disease, i.e. whether the symptoms of LUTS assessed by IPSS affect quality of life and subsequent treatment steps, then a hypothesis test is carried out in relation to the IPSS score with scores from the quality of life index using a test Spearman correlation. It was found that the correlation was not significant ( $\mathrm{p}>$ 0.05) with a correlation value of 0.073 , it was found that there was no relationship between the IPSS score and the Quality of Life score. This is different from that obtained by Christie S Mandang (2014) where there is a strong correlation between IPSS scores and QoL $(\mathrm{r}=0.481, \mathrm{p}=$ 0.003).$^{21}$ And also in CS Agrawal (2008) research, there is a strong correlation between IPSS scores with QoL $(r=0.429, \mathrm{p}=0.001) .^{23}$ These different results can be caused by various factors. We know that the quality of life index depends on the perception of each sample. And a person's perception can be influenced by emotional, cultural, social or ethnic status. In addition, methodologically the number of samples in this study was small and could influence the final results of the correlation test. Added to our research data (IPSS variable and quality of life), the distribution of scores looks uneven, this is evident from the frequency data table we presented earlier. Data accuracy also plays an important role in the correlation test results. It is important for researchers to present a questionnaire and provide a clear, straightforward, and accurate explanation of the questionnaire so that respondents provide targeted and unbiased answers. 


\section{SISS SRIWIJAYA JOURNAB OFSURGERY}

\section{Conclusion}

In this study there was no significant relationship between IPSS and QOL scores in BPH patients with LUTS.

\section{References}

1. Sausville J. Naslund M. Benign Prostatic Hyperplasia and prostase cancer: an overview for primary care physiacian. Int J Clin Pract. 2010;64(13):1740-1745

2. Miller J, Tarter TH. Combination therapy with dutasterid and tamsulosisn for the treatment of symptomatic enlarged prostate. Clin Interv Aging. 2009;4:251-8

3. Vasanwala F, Chen Wong. Benign prostatic hyperplasia and male lower urinary symptom: A guide for family physicians. Asian Journal Urology (2017);4:181-184

4. Tanguay $\mathrm{S}$ et al. Diagnosis and managemet of benign prostatic hyperplasia in primary care. Can Urol Assoc J 2009;3(3suppl2):s92-100

5. Praveen R. Benign Prostatic Hyperplasia:Updated Review. Int Res J Pharmacy 2013, 4 (8)

6. Drummond, M. F., McGuire, A. J., Black, N. A., Petticrew, M., \&McPherson, C. K. (1993). Economic burden of treating benign prostatic hyperplasia in the United Kingdom. Br J Urol, 71, 290-296.

7. Kortt, M. A., \& Bootman, J. L. (1996). The economics of benign prostatic hyperplasia treatment: A literature review. Clin Ther,18(6), 1227-1241.

8. Terai, A., Kakehi, Y., Terachi, T., \& Ogawa, O. (2000). National trend of management of benign prostatic hyperplasia in Japan during 1990s: Analysis of national health statistics. Hinyokika Kiyo, 46(8), 537-544.

9. Korea National Statistical Office. Population. (2001). Korea National Statistical Office, Seoul.

10. Homma, Y, Gotoh, M. Yokoyama O,et al. Outline of JUA clinical guideline for benign prostatic hyperplasia. Int J Urol, 2011;18(11):741-756

11. Ho CK, Habib FK. Estrogen and Androgen signaling in the pathogenesis of BPH. Nat Rev Urol .2011;8(1):29-41. 


\section{SISS SRIWIJAYA JOURNAB OFEURGERY}

12. Kapoor A. Benign Prosatic Hyperplasia (BPH) management in the primary care setting. Can J Urol.2012;19(suppl 1):10-17

13. Hines JEW. Symptom indices in bladder outlet obstruction. BJU 1996;77:494-1

14. Cockett ATK, Aso Y, Chatelain C. The International Consultation on benign prostatic Hyperplasia, Paris 1991. Scientific International.1991.

15. Shah y, Chikhlikar A, et al. Study of sonological correlation with IPSS score in benign prostatic hyperplasia patients. Panacea Journal of Medical Science, September-December, 2016;6 (3):164-166

16. Sarma AV, Wei TJ. Clinical Practice. Benign Prostatic Hyperplasia (BPH) and lower urinary tract symtomps. N Eng J Med 2012;367(3):248-257

17. Lee HW,Kim SA, nam JW, et al. The study about physical activity for subjects with prevention of benign prostate hyperplasia. Int Neurolo J. 201;18 (3):155-162.

18. Parsons JK. Benign Prostatic Hyperplasia and male lower urinary tract symtomps: epidemiology and risk factor. Curr Bladder Dysfunction Rep.2010;5(4):212-218.

19. Hofner K, Burkart M, Jacob G,et al. Safety and efficacy of tolertodine extended release in men with overactive bladder symtomps and presumed non-obstructive benign prosatic hyperplasia. World J Urol 2007 Dec;25(6):627-33.

20. Ramesh A, Kartheek S. Study of impact patient education on health related quality of life in benign prostatic hyperplasia (BPH) patients in a south indian teaching hospital. 2009. Asian Journal of Pharmaceutical and clinical research: 2(4): 97-103.

21. Cristie S, Monoarfa R, et al. Hubungan anatar skor IPSS dengan quality of life pada pasien BPH dengan LUTS yang berobat di poli bedah RSUP Prof. Dr. R. D. Kandou Manado. 2015. Jurnal e-Clinic (eCl), volume 3, Nomor 1:490-496.

22. Roehborn Claus G. Benign Prostatic Hyperplasia: An Overview. The university of Texas Southwestern Medical Center. Dallas, Tx, 2005.

23. Agrawal CS, Chalise PR et al. Correlation of prostate volume with International prostate symptom score and quality of life in men with benign prostatic hyperplasia. Nepal Med Coll J 2008;10 (2):104-107. 